J. Dhaka National Med. Coll. Hos. 2011; 17 (01): 29-32

Original article:

\title{
Correlation of birth weight with other anthropometric variables in detection of low birth weight (LBW) babies.
}

\author{
Reema Afroza Alia ${ }^{1}$, M. A Mannan², Kanij Fatema ${ }^{1}$, Fahmida Begum ${ }^{1}$, Russel \\ Siddique $^{1}$ \\ ${ }^{1}$ Medical Officer, Dept of Pediatrics, BSMMU,Dhaka, ${ }^{2}$ Ex-chairman of Pediatrics, BSMMU,Dhaka, ${ }^{3}$ Junior Consultant \\ (Padiatrics) Sonatola Health Complex, Bogura, ${ }^{4}$ Professor of Pediatrics, Dept of Pediatric Haemato- oncology, \\ BSMMU,Dhaka.
}

\begin{abstract}
:
Objective: To asses the correlation of birth weight with other anthropometric variables and their appropriateness in prediction and detection of low birth weight babies.

Methodology: It was a hospital-based cross-sectional observational study, conducted over 100 newborn babies within 24 hours of their birth. Birth weight and other anthropometric variables were recorded and analyzed with statistical package for social science (SPSS-17) and Student's t-test, Chi-squared ( $\left.\lambda^{2}\right)$, ANOVA and Pearson correlation tests were done to test the hypothesis and level of significance was set as $\mathbf{p}<0.05$.

Result: All the anthropometric variables were well correlated with birth-weight, irrespective of gestational age $(p<0.01)$. The highest correlation was found with chest circumference $(r=0.962)$, while the lowest correlation was observed with calf circumference $(\mathbf{r} \mathbf{0 . 9 2 3})$.

Conclusion: All anthropometric variables except calf circumference can be considered as appropriate indicators for identifying neonates require special attention and intervention for low birth weight (LBW) where weighing machine or facilities for ultrasonography is not readily available.

Key words: LBW, birth weight, anthropometric variable.
\end{abstract}

\begin{abstract}
Introduction:
Bangladesh is currently one of the very few countries in the world, which is on target for achieving the Millennium Development Goal (MDG) 4 relating to child mortality ${ }^{1}$. Perinatal and neonatal mortality are increasingly important public health issues in many developing countries, as post neonatal mortality rates fall ${ }^{2}$. Neonatal survival depends on both gestational maturity and birth weight and is not significantly better in babies who are LBW for gestational $\mathrm{age}^{3}$. The intrauterine milieu affects the health of an individual not only during fetal life but also throughout the postnatal stages of life ${ }^{4}$. In addition to its impact on infant mortality, LBW has been
\end{abstract}

Corresponding author: Dr. Reema Afrooz, FCPS, Medical Officer, Dept. of pediatrics, BSMMU, Dhaka, Bangladesh. email: reema.huq@yahoo.com associated with higher probabilities of infection, malnutrition and handicapped conditions during childhood (including cerebral palsy), mental deficiencies and problems related to behavior and learning during childhood ${ }^{5}$. In Bangladesh, the prevalence of low birth-weight is unacceptably high (varies between $23 \%$ and $60 \%$ ) which is more than twice the $15 \%$ threshold that indicates a public-health problem $^{6-8}$. Low birth-weight (LBW) has serious implications for the growth, development, health, and survival of children and adults ${ }^{9}$. So it is crucial to identify neonates with low birth weight and ensure their adequate service for survival and development. However in developing countries like Bangladesh and India 70-80\% of births take place at home and peripheral hospitals, taking accurate birth weight is a problem due to unavailability of weighing scale and trained personnel ${ }^{10}$. Several studies also have given the conclusion that the newborn's nutritional status is more 
important than birth weight alone for identifying perinatal risks ${ }^{11-12}$. Moreover the customary approach of comparing outcomes in 'small for gestation' with 'appropriate for gestation' infants, when the latter group comprises all from the $10^{\text {th }}$ through the 99th centile, has never been satisfactorily justified $^{13}$, which necessitate the determination of additional or alternative indices to improve this evaluation.

The current study was carried out with an aim to determine the most appropriate anthropometric parameter in the newborn to assess birth weight so that newborn with LBW can be identified and managed.

\section{Material \& Methods:}

The cross sectional observational study was conducted in the department of pediatrics and Obstetrics of Bangabandhu Sheikh Mujib Medical University (BSMMU), Dhaka, Bangladesh over a period of six months. One hundred live births were attended within 24 hours of birth and birth weight, mid-arm circumference, chest circumference, abdominal girth, thigh circumference, calf circumference, foot length, occipitofrontal circumference and supine length were recorded. Equipments used were a pediatric weighing machine, a flexible and non-stretchable measuring tape and a vertical measuring scale. All the data were edited and analysed with statistical package for social science-17 (SPSS-17) and Student's t-test, Chi-squared $\left(\lambda^{2}\right)$, ANOVA and Pearson correlation tests were done to test the level of significance.

\section{Result:}

All the anthropometric measurements were significantly higher in babies with normal birth weight compared to those in low birth weight babies ( $p$ < 0.001) (Table I). Table II shows association between birth-weight and gestational age. Of the 39 preterm babies $100 \%$ were low birth weight (LBW) while among the 58 term babies $77.5 \%$ were normal birth weight and $22.5 \%$ were low birth weight indicating that term babies tend to be of normal birth weight $(\mathrm{P}<0.001)$. All the anthropometric variables exhibited a significantly linear correlation with gestational age $(\mathrm{p}<0.001)$ (Table III).
In pre-term babies all the selected anthropometric variables, except calf circumference, had significant linear correlation with the birth-weight $(\mathrm{p}<0.01)$. In term babies all the anthropometric variables exhibited significantly linear correlations with the birth weight of babies $(p<0.01)$. In post-term babies no significant correlation was observed between the variables of interest (except supine length and weight, $p<0.05)$. However, all the anthropometric variables were found to be well correlated with birth-weight of babies, irrespective gestational age $(\mathrm{p}<0.01)$. The highest correlation coefficient was found between chest circumference and birthweight of babies $(r=0.962)$, while the lowest correlation coefficient was observed between calf circumference and birth weight of babies (r 0.923) (Table IV).

Table I. Comparison of anthropometric variables between LBW and normal weight babies

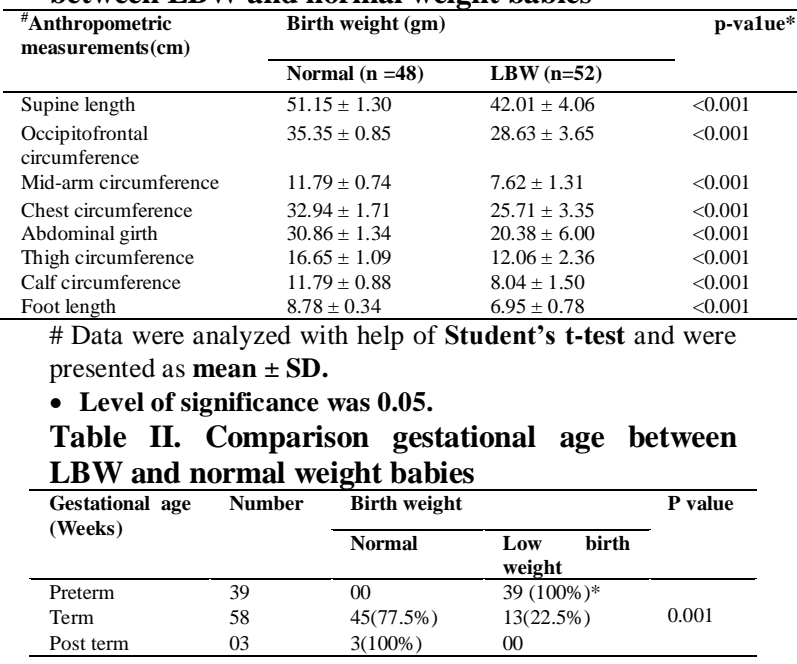

\# Data were analysed with help of Chisquared $\left(\lambda^{2}\right)$ and were presented as $\mathrm{n}(\%)$ $*$ Level of significance was 0.05 .

\begin{tabular}{|c|c|c|c|c|c|}
\hline $\begin{array}{l}\text { Table III. } \\
\text { anthropometric }\end{array}$ & $\begin{array}{r}\text { Asso } \\
\text { me }\end{array}$ & $\begin{array}{l}\text { ation } \\
\text { irement }\end{array}$ & betwee & & \\
\hline \#Anthropometric & Gestationa & & & $(\mathbf{r})^{*}$ & p- \\
\hline & $\begin{array}{l}\text { Pre-term } \\
(\mathrm{n}=39)\end{array}$ & Term $(=58)$ & $\begin{array}{l}\text { Post- term } \\
(=58)\end{array}$ & & \\
\hline Supine length & $40.5 \pm 2.9$ & $49.8 \pm 2.9$ & $53.0 \pm 1.2$ & 0.861 & $<0.001$ \\
\hline OFC & $27.3 \pm 3.1$ & $34.5 \pm 1.7$ & $36.1 \pm 0.3$ & 0.895 & $<0.001$ \\
\hline MAC & $7.1 \pm 0.6$ & $11.0 \pm 1.5$ & $12.8 \pm 0.5$ & 0.830 & $<0.001$ \\
\hline Chest circumference & $24.3 \pm 2.4$ & $31.9 \pm 2.4$ & $35.9 \pm 0.4$ & 0.879 & $<0.001$ \\
\hline Abdominal girth & $18.1 \pm 4.9$ & $29.7 \pm 2.6$ & $33.2 \pm 0.6$ & 0.894 & $<0.001$ \\
\hline Thigh circumference & $11.2 \pm 1.7$ & $15.9 \pm 1.5$ & $19.6 \pm 0.9$ & 0.855 & $<0.001$ \\
\hline Calf circumference & $7.5 \pm 1.0$ & $11.1 \pm 1.3$ & $13.6 \pm 0.5$ & 0.821 & $<0.001$ \\
\hline Foot length & $6.6 \pm 0.5$ & $8.4 \pm 0.6$ & $9.5 \pm 0.2$ & 0.853 & $<0.001$ \\
\hline Birth weight & $1615 \pm 412$ & $2803 \pm 411$ & $3136 \pm 902$ & 0.859 & $<0.001$ \\
\hline
\end{tabular}

\# Data were analysed with help of ANOVA 
statistics and were presented as mean \pm SD.

* Pearson correlation coefficient was used and was denoted by $r$.

**Level of significance was 0.05 .

Table IV. Correlation of birth weight with other anthropometric variables

\begin{tabular}{|c|c|c|c|c|c|}
\hline \multicolumn{3}{|c|}{ Correlated variables } & \multicolumn{3}{|c|}{ Correlation coefficients $(r)$} \\
\hline$(\mathbf{X})$ & (Y) & 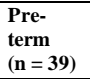 & $\begin{array}{l}\text { Term } \\
(\mathrm{n}=58)\end{array}$ & 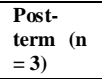 & $\begin{array}{l}\text { Overall } \\
\text { (N 100) }\end{array}$ \\
\hline Supine length & Weight & $0.852^{* * *}$ & $0.922^{* * *}$ & $0.999 *$ & $0.961^{* * *}$ \\
\hline $\mathrm{OFC}$ & Weight & $0.927 * *$ & $0.914 * *$ & $0.986^{\mathrm{NS}}$ & $0.950 * *$ \\
\hline MAC & Weight & $0.662^{* * *}$ & $0.919 * *$ & $0.960^{\mathrm{NS}}$ & $0.950^{* *}$ \\
\hline $\begin{array}{l}\text { Chest } \\
\text { circumference }\end{array}$ & Weight & $0.852^{* * *}$ & $0.863^{* *}$ & $0.951^{\mathrm{NS}}$ & $0.962^{* * *}$ \\
\hline $\begin{array}{l}\text { Abdominal } \\
\text { girth }\end{array}$ & Weight & $0.880^{* *}$ & $0.927 * *$ & $0.965^{\mathrm{NS}}$ & $0.949^{* *}$ \\
\hline $\begin{array}{l}\text { Thigh } \\
\text { circumference }\end{array}$ & Weight & $0.754^{* * *}$ & $0.916^{* * *}$ & $0.859^{\mathrm{NS}}$ & $0.953^{* *}$ \\
\hline $\begin{array}{l}\text { Calf } \\
\text { circumference }\end{array}$ & Weight & $0.304^{\mathrm{NS}}$ & $0.968 * *$ & $0.876^{\mathrm{NS}}$ & $0.923 * *$ \\
\hline Foot length & Weight & $0.683^{* * *}$ & $0.935 * *$ & $0.769^{\mathrm{NS}}$ & $0.951 * *$ \\
\hline
\end{tabular}

\section{Discussion:}

Low birth weight (LBW) is among the strongest determinants of infant mortality and morbidity, and the chances for intact survival of LBW infants is much lower in developing countries due to inadequate or limited medical care including proper antenatal care ${ }^{14}$. The current study was conducted to identify the suitable parameters to predict low birth weight babies and those who are at risks of adverse antenatal, perinatal and postnatal outcome.

In Bangladesh, the prevalence of low birthweight is unacceptably high (varies between $23 \%$ and $60 \%)^{6-8}$, in the current study $38 \%$ of the babies were with low birth weight (15002500 gms) and $14 \%$ with every low birth weight (900-1500 gms).

Considering that birth weight is not fully satisfying indices for prediction of perinatal risk and long term out come, an alternative or additive parameter has been searched for a long time. A series of anthropometric variables (Midarm circumference, chest circumference, abdominal girth, thigh circumference, calf circumference, foot length, occipitofrontal circumference and supine length) had been identified as suitable by different authors with variable sensitivity and specificity ${ }^{13-24}$.

In the current study, all the anthropometric measurements were significantly higher in babies with normal birth weight compared to those in low birth weight babies ( $p<0.001$ ), similar association was also found between birth-weight and gestational age $(\mathrm{P}<0.001)$, Anthropometric variables exhibited a significantly linear correlation with gestational age indicating that higher the gestational age the greater are the anthrpometric measurements $(p<0.001)$ all the anthropometric variables were found to be well correlated with birth-weight of babies, irrespective gestational age $(\mathrm{p}<0.01)$. The highest correlation coefficient was found between chest circumference and birth-weight of babies $(r=0.962)$, while the lowest correlation coefficient was observed between calf circumference and birth weight of babies ( $\mathrm{r}$ 0.923).

Dhar et $\mathrm{al}^{20}$ (2002) have found a similar result and chest circumference (CC) was the best detector of birth-weight, where as Kadam et al ${ }^{18}$ found relatively highest correlation between birth weight $\&$ thigh circumference (T.C.) \& next with chest circumference (CC). A study conducted over Bangladeshi population, by Zakir et al, (Huque and Hussain, 1991) ${ }^{25}$ showed that a chest circumference of $30.14 \mathrm{~cm}$, a thigh circumference of $14.56 \mathrm{~cm}$ and a mid-arm circumference of $8.90 \mathrm{~cm}$ corresponded well with a birth weight of 2,500 gm. On this basis sensitivity, specificity and predictive values of the chest circumference was better than the other two measurements. However, the mid-arm circumference was observed to be more reliable than the other two measurements for detecting birth weight less than 2,000 gm.

In the current study, in pre-term babies all the selected anthropometric variables, except calf circumference, were found to bear significantly linear correlation with the birth-weight of babies $(\mathrm{p}<0.01)$ and in full-term babies all the anthropometric variables exhibited significantly linear correlations with the birth weight of babies ( $\mathrm{p}<0.01)$. In post-term babies no significant correlation was observed between the variables of interest (except supine length and weight, $\mathrm{p}<$ $0.05)$ probably due to very small numbers of post-term babies. Yau \& Chang ${ }^{25}$ in similar type of study over Chinese newborn babies found that, except for the head circumference/ length ratio, all other indices showed a significant correlation

with gestational age and a weaker correlation coefficient of the mid-arm circumference/head circumference ratio was found comparing with the pre-term group. $\mathrm{HC}$ and $\mathrm{TC}$ appears to be better indicators for picking up LBW babies and MAC and CFC appears to be better in picking up very LBW babies ${ }^{27}$.

So, a series of anthropometric measurements (Mid-arm circumference, chest circumference, abdominal girth, thigh circumference, foot length, 
occipitofrontal circumference and supine length) have been found to be suitable and additional alternative indices for predicting birth weight and adverse perinatal out come.

\section{Conclusion:}

Mid-arm circumference (MAC), chest circumference (CC), abdominal girth (AG), thigh circumference (TC), foot length (FL), occipitofrontal circumference (OC) and supine length (SL) all are correctly correlated with birth weight and can be considered as appropriate indicators for identifying neonates require special attention and intervention for low birth weight (LBW) where weighing machine or facilities for ultrasonography is not readily available.

\section{Reference:}

1. Arifeen SE Bangladesh needs to sustain its efforts to achieve MDG 4 of reducing under-five mortality by two-thirds. Child Health and Mortality Journal of Health, Population and Nutrition 2008; 26(3)

2. Costello A. Perinatal health in developing countries.Transactions of the Royal Society for Tropical Medicine and Hygiene, 1993, 87: 1-2.

3. Crowther ME. A retrospective study of all low birth weight preterm babies born in between 1980-1989. in Bmjr JR Army MED Corps. 1990; 136: 43-49.

4. http://www.toronto.ca/health/low_birth_weight/p df/lbw part 1b.pdf.

5. Berkowitz GS, Papiemik E. Epidemiology of preterm birth. Epidemiol Rev. 1993; 15: 414-43.

6. Dunin-Wasowicz D, Rowecka-Trzebicka K, Milewska- Bobula B, Kassur-Siemienska B, Bauer A,Idzik M, Lipka B, Marcinski P. Risk factors for cerebral palsy in very low birth weight infants in the 1980s and 1990s. J Child Neurol. 2000; 15: 414-20.

7. Atlas of South Asian women and children. Kathmandu, United Nations Children's Fund, 1996.

8. The progress of nations. New York, United Nations Childrens Fund, 1997.

9. Nahar N. Recent trends in perinatal health in South Asia: Bangladesh. In: Costello A, Manandhar D, eds. Improving newborn infant health in developing countries. London, Imperial College Press, 1999.

10. Salam KMA, Haseen F, Yusuf HKM. Torlesse4http://203.190.254.12/images/Capgan8t h_OP-Day-2_SS-13.pdf National Low Birthweight Survey of Bangladesh, 2003-2004.

11. Bhargava SK, Ramji S, Kumar A, Marwah J, Sachdev HPS. Mid Arm \& Chest circumference at birth as predictors of Low Birth Weight \& Neonatal Mortality in the community. British Medical Journal 1985; 291: 1617-19.

12. Patterson RM, Pouliot MR. Neonatal morphometrics and perinatal outcome: who is growth retarded? Am J Obstet Gynecol. 1987;157(3):691-3.

13. Patterson RM, Prihoda TJ, Gibbs CE, Wood RC. Analysis of birth weight percentile as a predictor of perinatal outcome. Obstet Gynecol. 1986;68(4):459-63.

14. Elshibly EM and Schmalisch G, The effect of maternal anthropometric characteristics and social factors on gestational age and birth weight in Sudanese newborn infants. BMC Public Health. 2008; 8: 244.

15. Morley R, Brooke OG, Cole TJ, Powell R, Lucas A Birthweight ratio and outcome in pretermn infants Arch Dis Child 1990 65: 30-34.

16. Sharma JN, Saxena S, Sharma U. Thigh circumference at birth as the best predictor of low birth weight babies. Indian Pediatr 1989;26:1821.

17. Kulkarni ML, Rehman M. Neonatal assessment beyond birth weight. Indian Pediatr 1991;28:92931.

18. Kadam YR, Somaiya P, Kakade SV. A study of surrogate parameters of birth weight. Indian $\mathbf{J}$ Commun Med 2005;30:89-91.

19. Samal GC, Swain AK. Calf circumference as an alternative to birth weight for identification of low birth weight babies. Indian Pediatr 2001;38:275-7.

20. Dhar B, Mowlah G, Nahar S, Islam N. Birthweight status of newborns and its relationship with other anthropometric parameters in a public maternity hospital in Dhaka, Bangladesh. J Health Popul Nutr. 2002 Mar;20(1):36-41.

21. Landicho B, Lechtig A, Klein E. Anthropometric indicator of low birth weight. J Trop Pediatr 1985;31:301-05.

22. Ramaiya C, Msamanga G, Massawe S, et al. Newborn's arm circumference as a screening tool of low birth weight in Temeke District, Dar es Salaam, Tanzania. Trop Geogr Med 1994;46:318-21.

23. Sacher AC, Soni RK, Singh B, et al. Consistent accuracy of mid arm circumference and calf circumference as birth weight surrogates during first few days. Indian J Matern Child Health 1994;5:41-4.

24. Bhargava SK, Ramji S, Kumar A, et al. Midarm and chest circumference at birth as predictor of low birth weight and neonatal mortality in the community. Br Med J 1985;291:1617-19.

25. Huque F and Hussain AMZ, Detection of Low Birth-Weight New Born Babies by Anthropometric Measurements in Bangladesh Indian J Pediatr 1991; $58:$ 223-231.

26. Yau KI, Chang MH. Weight to length ratio - a good parameter for determining nutritional status in preterm and full-term newborns. Acta Paediatr. 1993;82(5):427-9.

27. Taksande A, Vilhekar KY, Chaturvedi P, Gupta S and Deshmukh P Predictor of Low Birth Weight Babies by Anthropometry Journal of Tropical Pediatrics Vol. 53, No. 6 pp:620-23. 